\title{
FORMIC ACID, ETHANOL IN VYCOR GLASS, AND WATER IN ALUMINOSILICATE ZEOLITES*
}

\author{
C.-K. Loong, F. Trouw and L. E. Iton \\ Argonne National Laboratory \\ Argonne, IL 60439 U. S. A.
}

\section{IECEIVEO \\ NOV 081993 \\ OSTI}

\section{MASTER}

DISTRIBUTION OF THIS DOCUMENT IS UNLIMITED

Presented at

A NATO Advanced Research Workshop on "Hydrogen-Bond Networks"

August 16-22, 1993

Cargese, Corsica, France

Proceedings to be published by Kluwer Academic Publishers

*Work supported by U. S. Department of Energy, BES, contract No. W-31-109-ENG-38

\section{DISCLAIMER}

\begin{abstract}
This report was prepared as an account of work sponsored by an agency of the United States Government. Neither the United States Government nor any agency thureof, nor any of their employees, makes any warranty, express or implied, or assumes any legal liability or responsibility for the accuracy, completeness, or usefulness of any information, apparatus, product, or process disclosed, or represents that its use would not infringe privately owned rights. Reference herein to any specific commercial product, process, or service by trade name, trademark, manufacturer, or otherwise does not necessarily constitute or imply its endorsement, recommendation, or favoring by the United States Government or any agency thereof. The views and opinions of authors expressed herein do not necessarily state or reflect those of the United States Government or any agency thereof.
\end{abstract}




\title{
FORMIC ACID, ETHANOL IN VYCOR GLASS, AND WATER IN ALUMINOSILICATE ZEOLITES
}

\author{
C.-K. Loong, F. Trouw and L. E. Iton \\ Argonne National Laboratory \\ Argonne, IL 60439 U. S. A.
}

\begin{abstract}
We present the results of incoherent inelastic neutron-scattering experiments on formic acid, ethanol in vycor glass, and water in aluminosilicate zeolites performed at Argonne's spallation neutron source, IPNS. The forming and breaking of hydrogen bonds are discussed in terms of translational and rotational diffusion, and vibrational footprints of various molecular species in these systems.
\end{abstract}

\section{Introduction}

The structure and dynamics of hydrogen-bond networks play an important role in the physical and chemical properties of many molecular liquids and solids. Water is the premier example for which hydrogen bonding is known to be strong and complex. Even for pure water, a theoretical model for a coherent interpretation of most of its anomalous thermodynamic properties is lacking. In aqueous biological systems the rapidly fluctuating, tetrahedrally coordinated three-dimensional $\mathrm{H}$-bond network of water molecules supports important hydrophobic and hydrophilic interactions with solute molecules. As a first step to understand the nature of this complex behavior we have studied the H-bond dynamics in some simple carboxylic acids and alcohols, and in hydrated molecular sieves.

Spallation neutron sources equipped with low-temperature moderators provide high fluxes of cold-to-epithermal neutrons. Neutron spectroscopy using these pulsed sources enables the measurement of hydrogen vibrational density of states over a wide range of energy and momentum transfer which reflects the formation and breaking of $\mathrm{H}$-bonds due to diffusional and vibrational motion of the molecules. In this paper we report the results of incoherent inelastic neutron-scattering experiments performed at Argonne's spallation neutron source IPNS on formic acid, ethanol in vycor glass, and water in aluminosilicate zeolites.

\section{Formic acid}

Hydrogen bonding in formic acid $(\mathrm{HCOOH})$ is simpler than that in water, since formic acid has only one donor and one receptor site per molecule. As a result of $\mathrm{H}$-bond formation in the crystalline and dimer phases, the $\mathrm{O}-\mathrm{H}$ distances $(\approx 1.04 \AA)$ are significantly larger than that $(0.984 \AA)$ in the isolated monomer. [1] The O-H streiching frequency decreases from $442 \mathrm{meV}$ for the monomer to about $341 \mathrm{meV}$ in the crystalline phase.[2-4]The crystal structure of formic acid, obtained from neutron powder diffraction 


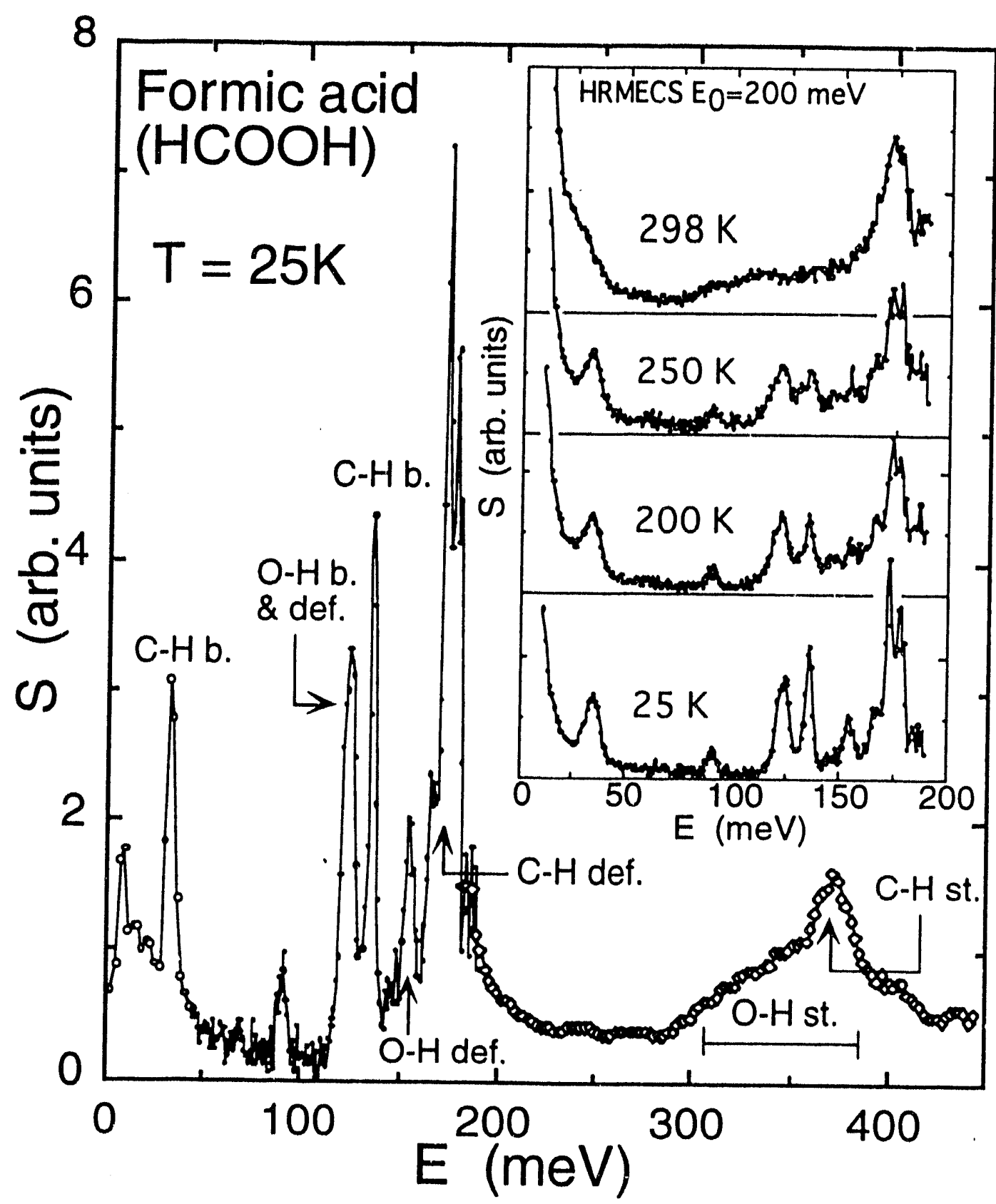

Figure 1. The neutron dynamic structure factor of formic acid at $25 \mathrm{~K}$. Data below $50 \mathrm{meV}$ were collected using the QENS spectrometer. In the regions of 50 $190 \mathrm{meV}$ and $190-450 \mathrm{meV}$ data were obtained using the HRMECS spectrometers with incident energies of 200 and $600 \mathrm{meV}$, respectively. Inset: The temperature dependence of the spectra between $25 \mathrm{~K}$ and room temperature.

of DCOOD [5] and x-ray single-crystal diffraction of $\mathrm{HCOOH}$ at $\mathrm{T}<100 \mathrm{~K}$ [6], consists of infinite $\mathrm{H}$-bonded chains tightly packed in layers parallel to the $(100)$ planes. The chain structure is consistent with the cis- $\beta_{1}$ conformation which ab initio calculations have indicated to be the most stable structure.[7] Recent neutron diffraction measurements of formic acid at $18^{\circ}, 34^{\circ}$ and $49^{\circ} \mathrm{C}$ indicated that this chain structure 
persists in the liquid state.[8] However, differences in the stabilization energy among various cis- and trans-conformations of formic acid are small. Thus far, attempts to differentiate the components of multiple conformations of formic acid molecules in the solid phase at elevated temperatures, by diffraction and spectroscopic investigations, have been unsuccessful. Our goal is to determine the temperature dependence of the vibrational density-of-states of solid and liquid formic acid over a wide range of energies.

The dynamic structure factors, $S(E)$, obtained from measurements using the HRMECS and the QENS spectrometers at IPNS are shown in Fig. 1. The prominent features in the spectra, labeled according to previous Raman and IR results reported by Mikawa and coworkers [9] and by Zelsmann and Marechal [4], arise mainly from atomic motions involving the $\mathrm{C}-\mathrm{H}$ and $\mathrm{O}-\mathrm{H}$ bonds. In general, the $\mathrm{C}-\mathrm{H}$ band widths are smaller, indicating less dispersive motion of the $\mathrm{C}-\mathrm{H}$ bonds. The $\mathrm{O} \cdot \mathrm{H}$ bonds are coupled to the neighboring molecules through $\mathrm{H}$-bonding, therefore their motions are subject to strong fluctuations and cooperative energy transfers along the chains. The large width of the O$\mathrm{H} \cdots \mathrm{O}$ stretch vibration $(300-400 \mathrm{meV})$ is consistent with the IR results $[4,9]$. As the temperature rises, orientational disorder through hindered molecular rotations enhances the breaking (and re-combination) of $\mathrm{H}$-bonds. This effect is manifested by the more pronounced broadening of the $\mathrm{O}-\mathrm{H}$ deformation bands as compared to the $\mathrm{C}-\mathrm{H}$ bands with increasing temperature (see inset of Fig. 1). Complete damping of the $\mathrm{C}-\mathrm{H}$ modes at 30,135 and $373 \mathrm{meV}$ occurs only in the liquid state by positional disorder.

\section{Ethanol}

Ethanol $\left(\mathrm{C}_{2} \mathrm{H}_{5} \mathrm{OH}\right)$ is a simple hydrogen bonded alcohol where the hydrogen atom of one $\mathrm{OH}$ group is weakly bound to the oxygen atom of another molecule. The relatively small pore size ( $\approx 50 \AA$ diameter) of Vycor glass in conjunction with its porosity $(=30 \%)$ makes the system of ethanol in Vyror an ideal candidate for studying hydrogen bonding in restricted geometry. Fig. 2 displays the dynamic structure factors for bulk ethanol i...d for one statistical monolayer of ethanol molecules physisorbed on the porous surface of a vycor glass $\left(196 \mathrm{~m}^{2} / \mathrm{g}\right)$. It is interesting to note that at $15 \mathrm{~K}$ the spectra of bulk and physisorbed ethanol are quite similar. At $15 \mathrm{~K}$ bulk ethanol exhibits a monoclinic crystal structure in which two molecules are joined by $\mathrm{H}$ bonds to form infinite chains.[10] The resemblance of the vibrational spectra in Fig. 2 thus suggests a similar H-bonded chain structure for ethanol in the bulk solid as well as in the monolayer on the vycor pore surface at low temperatures.

The influence of $\mathrm{H}$-bonding on surface melting of ethanol on graphite have recently studied by Herwig and Trouw. [11] Neutron diffraction data indicate that physisorbed ethanol forms a two-dimensional lattice commensurate to the graphite (001) planes. The layer structure is stabilized by zigzag chains of molecules joined by $\mathrm{H}$-bonds. Using the method of molecular dynamics simulation, these authors developed a model for melting of ethanol on graphite. At pre-melting temperatures internal molecular rotations about the $\mathrm{C}-\mathrm{O}$ axis give rise to orientational disorder and defects but the system maintains to a large extent the hydrogen bonded network structure. Melting occurs at a high enough temperature permitting large-scale breaking of the hydrogen bonds as well as positional disorder. The 2-D film melts at a temperature $50 \mathrm{~K}$ above the melting point of bulk ethanol. This unique behavior is due to the C-O bond rotation which is permitted in the 
2-D film but not in the 3-D crystal, resulting in a reduced entropy of melting for the 2-D film compared to the bulk material.

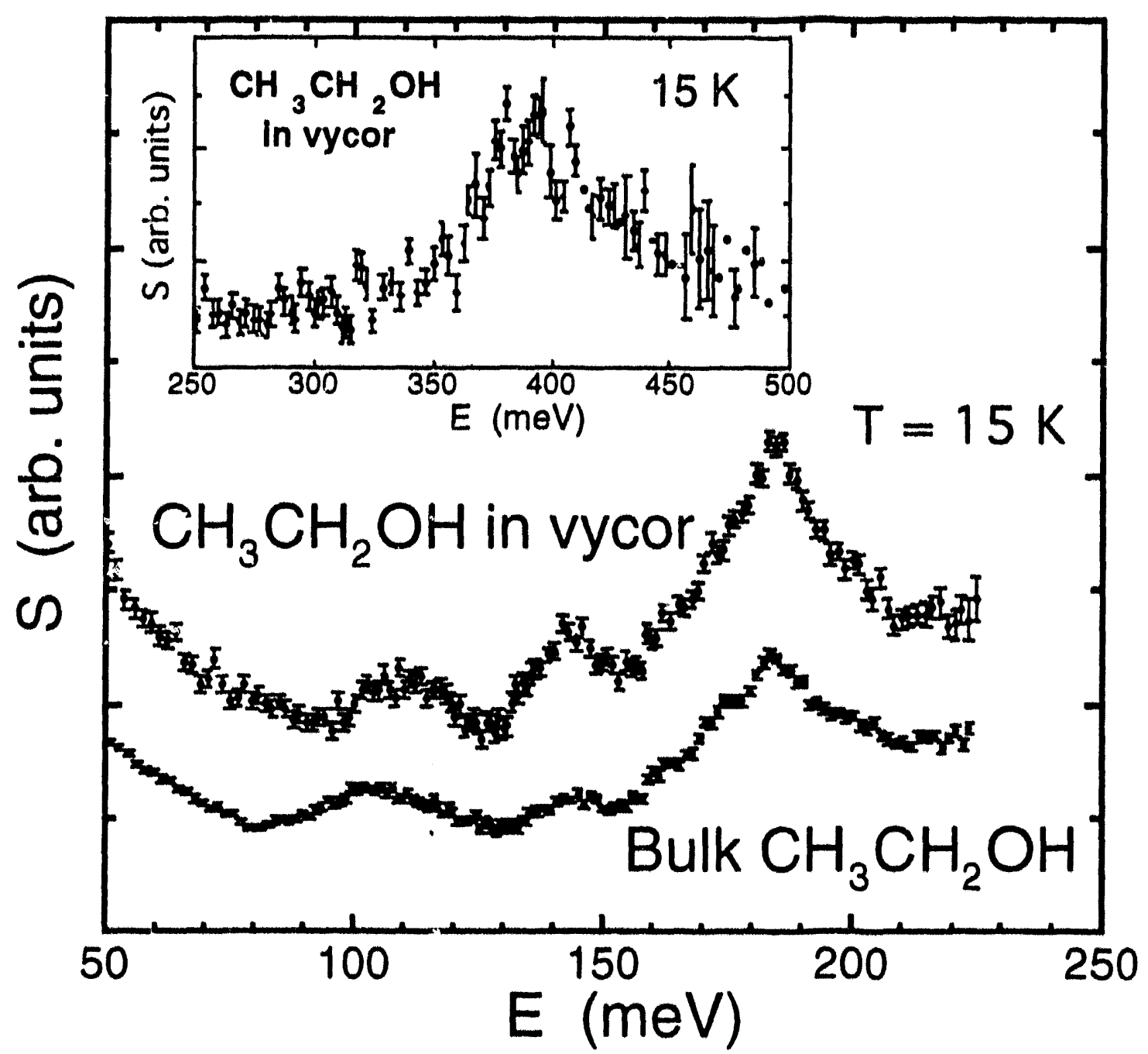

Figure 2. The neutron dynamic structure factors of bulk ethanol and one physisorbed monolayer of ethanol in vycor glass at $15 \mathrm{~K}$. Background scattering from sample holders and/or dry vycor glass has been removed.

The situation of ethanol physisorbed on vycor can be contrasted by the case of a non$\mathrm{H}$-bonded system, n-butane $\left(\mathrm{C}_{4} \mathrm{H}_{10}\right)$. The neutron spectra for bulk butane and a physisorbed monolayer of butane in vycor, obtained under identical experimental conditions as the ethanol measurements, exhibit striking differences (see Fig. 3), i.e., the torsional and vibrational bands of physisorbed butane molecules are broadened significantly and shifted in energy relative to the spectra for bulk solid. In fact, the band widths of butane in vycor are comparable to those of liquid butane [12] because, in the absence of $\mathrm{H}$-bond connectivity, the random porous surfaces in a vycor glass impose orientational and positional disorder to the absorbed molecules, resulting in a liquid-like excitation spectrum. 




Figure 3. The neutron dynamic structure factors of bulk $n$-butane and one physisorbed monolayer of butane in vycor glass at $T \leq 15 \mathrm{~K}$. Background scattering from sample holders and'or dry vycor glass has been removed.

\section{Water in aluminosilicate zeolites}

The presence of aluminum in the tetrahedral silicate network gives zeolites a negative framework charge which must be compensated by non-framework cations, or by protons which bond to framework oxygen atoms adjacent to the aluminum substituent. This results in zeolites usually possessing strongly hydrophilic character. The microporous structures results typically in a Type I adsorption isotherm with micropore filling at low vapor pressure for water and other small molecule adsorbates, see Fig. 4. Adsorbed water strongly hydrates the charge balancing cations rather than coordinating directly to the framework. Accordingly, the fluid content of the zeolite micropores resembles a concentrated electrolyte solution. On the other hand, aluminophosphate molecular sieves have neutral frameworks. There are no charge compensating cations, but the alternation of aluminum and phosphorous in the tetrahedral network gives rise to a dipolar framework. In the case of $\mathrm{AlPO}_{4}-5$, the structure causes the dipoles to be aligned and the material has a permanent net dipole moment. The behavior of water adsorbed in such neutral dipolar molecular sieve materials is not obvious a priori, and the degree of hydrophilicity varies with the structure of the aluminophosphate. Therefore, the 
characteristics of the water adsorption isotherms are variable. In particular, the water adsorption isotherm for $\mathrm{AlPO}_{4}-5$ is quite unusual. At low partial pressure, it has the shape characteristic of a hydrophobic adsorbent, but at higher partial pressures $\left(\mathrm{p} / \mathrm{p}_{0}>\right.$ 0.2 ), there is a large uptake of water with filling of the micropores. The isotherm shape is reminiscent of capillary condensation, a phenomenon usually associated with mesoporous adsorbents (pore diameters $220 \AA$ ) rather than with microporous materials such as $\mathrm{AlPO}_{4}-5$ which has one-dimensional 12-ring channels of $7.3 \AA$ in diameter. Direct coordination of $\mathrm{H}_{2} \mathrm{O}$ molecules to framework $\mathrm{Al}$ atoms has also been established for some aluminophosphates, e.g., VPI-5. This kind of framework coordination is unknown in the aluminosilicate zeolites.



Figure 4. $\mathrm{H}_{2} \mathrm{O}$ adsurption isotherm for some aluminosilicate zeolites and aluminophosphate molecular sieves. [13]

Interaction of water with the hydroxyl groups in $\mathrm{H}$-mordenite, $\mathrm{H}_{8}\left(\mathrm{AlO}_{2}\right)_{8}\left(\mathrm{SiO}_{2}\right)_{40}$, has recently been investigated by neutron diffraction [14] and inelastic scattering [15]. The inelastic spectra of hydrated $\mathrm{H}$-mordenite were compared with the corresponding spectra of the anhydrous zeolite and of ice to allow for assignments of the observed vibrational features to hydroxonium $\left(\mathrm{H}_{3} \mathrm{O}^{+}\right)$and other $\mathrm{H}_{2} \mathrm{O} \mathrm{H}$-bonded dydroxyl groups. We have performed inelastic neutron-scattering measurements on both $\mathrm{H}$ - and $\mathrm{Na}$-mordenite over a wide range of energies. This zeolites exhibit a pore structure consisting of onedimensional 12-ring elliptical channels $(7.0 \times 6.5 \AA)$ (along with small aperture side pockets which are not usually adsorbate diffusion pathways). 
The hydrogen density-of-states of water (loaded at a partial pressure of $15 \%$ ) in $\mathrm{H}$ - and $\mathrm{Na}$-mordenite at $15 \mathrm{~K}$, obtained from chopper spectrometer measurements, are shown in Fig. 5. The low-energy ( $<40 \mathrm{meV}$ ) density-of-states (not shown) were determined using the QENS spectrometer with better energy resolution. The observed frequencies and some proposed assignments are given in Table I. Comparison of the $\mathrm{H}$ - and $\mathrm{Na}$ mordenite spectra should provide a more definite distinction of vibrational features unique to $\mathrm{H}_{3} \mathrm{O}^{+}$. Our assignments differ somewhat from those given by Jobic et al. [14] in this regard.
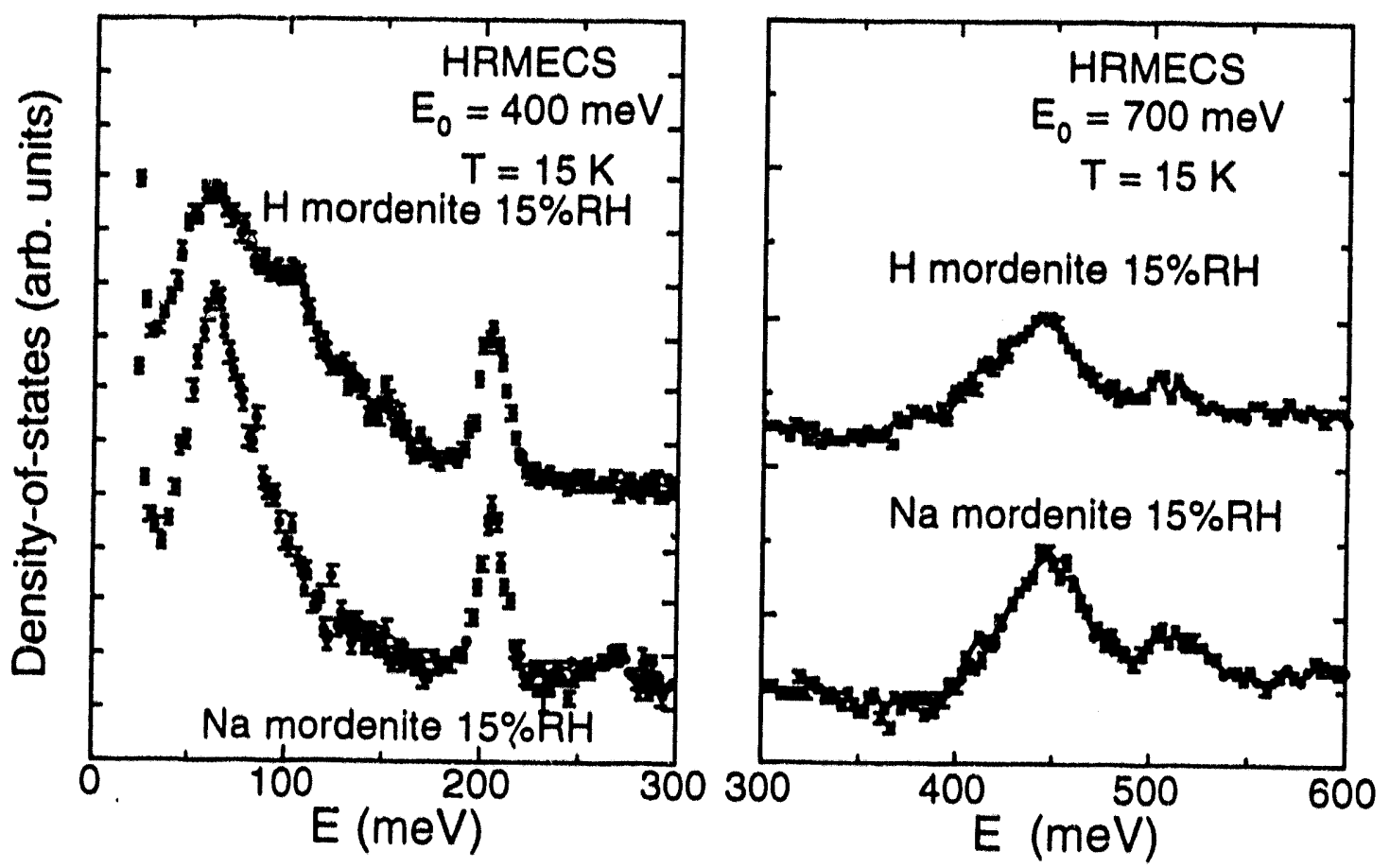

Figure 5. The hydrogen densities-of-states of $\mathrm{H}$ - and Na-mordenite at $15 \mathrm{~K}$.

\section{Future studies}

Inelastic neutron scattering is a useful tool for investigation of H-bond networks in simple substances such as those discussed here, as well as in complex biological systems. Experiments performed at spallation neutron sources provide a unified characterization of the dynamics over a wide range of energies ranging from diffusional motion to internal vibrations. The observed neutron spectra not only yield information complementary to IR and Raman measurements but also can afford quantitatively comparison with results from either analytic calculations or computer simulations. We have also performed quasielastic scattering experiments on the aforementioned systems in an attempt to understand the translational and rotational diffusion of $\mathrm{H}$-bonded molecules. Our study of hydration process in zeolites has been extended to aluminophosphate molecular sieves such as $\mathrm{AlPO}_{4}-5$. Molecular dynamics simulations of these systems are currently under way. 
Table I. Observed frequencies and peak assignments for inelastic neutron spectra of water adsorbed on Na-mordenite and $\mathrm{H}$-mordenite

\begin{tabular}{|c|c|c|}
\hline $\begin{array}{l}\text { Na-Mordenite } \\
\text { Energy (meV) }\end{array}$ & $\begin{array}{c}\text { H-Mordenite } \\
\text { Energy (meV) }\end{array}$ & Assignment \\
\hline 9 & 9 & Translation of $\mathrm{H}$ bonded $\mathrm{H}_{2} \mathrm{O}$ \\
\hline 15 & $\begin{array}{l}16 \\
48\end{array}$ & $\begin{array}{c}\text { Translation of } \mathrm{H}_{2} \mathrm{O} \text { or } \mathrm{H}_{3} \mathrm{O}^{+} \\
\text {Bridging } \mathrm{OH} \text { group }\end{array}$ \\
\hline 57 & 59 & $\mathrm{H}_{3} \mathrm{O}^{+}$or bound $\mathrm{H}_{2} \mathrm{O}$ torsion \\
\hline 67 & 66 & Torsion of $\mathrm{H}$-bonded $\mathrm{H}_{2} \mathrm{O}$ \\
\hline 76 & & Torsion of $\mathrm{H}_{2} \mathrm{O}$ bound to $\mathrm{Na}^{+}$ \\
\hline & 100 & $\mathrm{H}_{2} \mathrm{O}$ bound to bridging $\mathrm{OH}$ \\
\hline & 130 & Framework $\mathrm{OH}$ bend \\
\hline & 155 & $\mathrm{H}_{3} \mathrm{O}+$ bend \\
\hline 206 & 206 & $\mathrm{H}_{2} \mathrm{O}$ bend \\
\hline \multirow[t]{2}{*}{440} & 440 & $\mathrm{H}_{2} \mathrm{O}$ stretch \\
\hline & 457 & Framework $\mathrm{OH}$ stretch \\
\hline
\end{tabular}

\section{Acknowledgment}

We thank D. J. LePoire and K. Bradley for their assistance in the neutron experiments. Work performed at Argonne National Laboratory is supported by the U. S. DOE, Office of Basic Energy Sciences, under the contract No. W-31-109-ENG-38.

References

1. A. Almenningen, O. Bastiansen, and T. Motzfeldt, Acta Chem. Scand. 23, 2848 (1969).

2. J. E. Bertie and K. H. Michaelian, J. Chem. Phys. 76, 886 (1982).

3. R. C. Millikan and K. S. Pitzer, J. Amer. Chem. Soc. 80, 3515 (1958).

4. H. R. Zelsmann, Y. Marechal, A. Chassson, and P. Faure, J. Mol. Struct. 29, 357 (1975).

5. A. Albinati, K. D. Rouse, and M. W. Thomas, Acta Cryst. B34, 2188 (1978).

6. I. Nahringbauer, Acta Cryst. B34, 314 (1978).

7. A. Karpfen, in Quantum Chemistry of Polymers - Solid State Aspects, Ed. J. Ladik et al. (D. Reidel Publishing Co., 1984), p. 33.

8. G. I. Swan, in Hydrogen-Bonded Liquids, Ed. J. C. Dore and J. Teixeira (Kluwer, Dordrecht, The Netherlands, 1991) p. 139.

9. Y. Mikawa, J. W. Brasch, and R. J. Jakobsen, J. Mol. Spect. 24, 314 (1967).

10. P.-G. Jönnson, Acta Cryst. B32, 232 (1976).

11. K. W. Herwig and F. Trouw, Phys. Rev. Lett. 69, 89 (1992).

12. W. B. Nelligan, D. J. LePoire, C.-K. Loong, T. O. Brun, and S. H. Chen, Nucl. Instru. Methods, A254, 563 (1987).

13. M. E. Davis, C. Montes, P. E. Hathaway, J. P. Arhancet, D. L. Hasha, and J. M. Garces, J. Amer. Chem. Soc. 111, 3919 (1989).

14. M. Czjzek, H. Jobic, A. N. Fitch, and T. J. Vogt, J. Phys. Chem. 96, 1535 (1 y92).

15. H. Jobic, M. Czjzek, and R. A. van Santen, J. Phys. Chem. 96, 1540 (1992). 


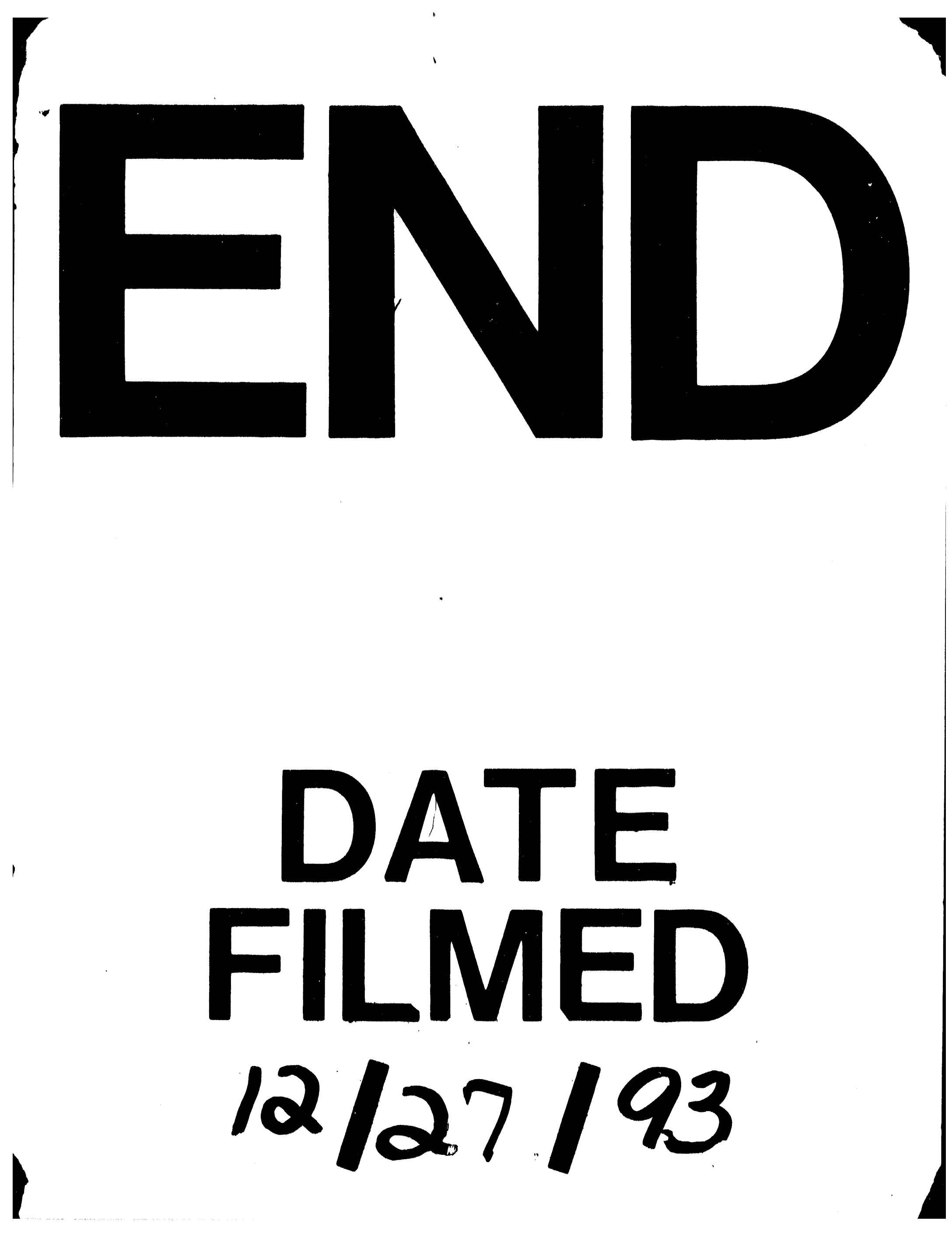


